\title{
Composition and Antimicrobial Activity of Essential Oils from
}

\author{
Leaves, Twigs and Ripe Fruits of Magnolia grandis
}

(Hu \& W.C. Cheng) V.S.Kumar in Ha Giang Province of Vietnam

\author{
Chu T. T. Ha $\oplus^{1,2}$, Le N. Diep $\oplus^{1}$, Dinh T. T. Thuy $\oplus^{3}$, Trinh N. Bon $\oplus^{4}$, \\ Le T. T. Cham $\oplus^{5}$ and William N. Setzer $\oplus^{6,7}$
}

${ }^{1}$ Institute of Ecology and Biological Resources, Vietnam Academy of Science and Technology (VAST), 18 Hoang Quoc Viet, Cau Giay, Ha Noi 10072, Vietnam

${ }^{2}$ Graduate University of Science and Technology, VAST, 18 Hoang Quoc Viet, Ha Noi 10072, Vietnam

${ }^{3}$ Institute of Natural Product Chemistry, VAST, 18 Hoang Quoc Viet, Ha Noi 10072, Vietnam

${ }^{4}$ Silviculture Research Institute, 46 Duc Thang, Bac Tu Liem, Ha Noi 10056, Vietnam

${ }^{5}$ Vietnam National University of Agriculture, Trau Quy, Giam Lam, Ha Noi 10056, Vietnam

${ }^{6}$ Aromatic Plant Research Center, 230 N 1200 E, Suite 100, Lehi, UT 84043, USA

${ }^{7}$ Department of Chemistry, University of Alabama in Huntsville, Huntsville, AL 35899, USA

(Received December 22, 2021; Revised January 28, 2022; Accepted February 02, 2022)

\begin{abstract}
The leaves, twigs and ripe fruits of Magnolia grandis (Hu \& W.C.Cheng) V.S.Kumar, growing wild in Ha Giang Province of Vietnam, were hydrodistilled to obtain essential oils which had the respective average yields of $0.09 \%, 0.25 \%$ and $0.62 \%(\mathrm{v} / \mathrm{w})$, calculated on a dry weight basis. The oils were analyzed using gas chromatography-flame ionization detector (GC-FID) and gas chromatography-mass spectrometry (GC-MS). Major components of these three oil samples were: $\alpha$-pinene $(11.8 \%)$, linalool $(15.4 \%)$ and $(E)$ - $\beta$-caryophyllene (10.7\%) (leaf oil); $\alpha$-pinene (42.8\%) and $\beta$-pinene (23.7\%) (twig oil); $\alpha$-pinene (52.2\%) (ripe fruit oil). The essential oils from leaves showed stronger inhibitory effects on the seven tested microorganism strains than those from twigs and ripe fruits. To our best knowledge, this is the first time that information on essential oils of M. grandis leaves, twigs and ripe fruits is reported.
\end{abstract}

Keywords: Magnolia grandis; antimicrobial activity; essential oil composition; $\alpha$-pinene. (C) 2022 ACG Publications. All rights reserved.

\section{Plant Source}

In the framework of intensive studies on plant resources containing essential oils of Magnolia species in Vietnam, we investigated composition and antimicrobial activity of essential oils from leaves, twigs and ripe fruits of M. grandis in Ta Poc mountains, Tung Vai Commune, Quan Ba District, Ha Giang Province $\left(23^{\circ} 03^{\prime} 21.3^{\prime \prime} \mathrm{N}, 104^{\circ} 50^{\prime} 50.7^{\prime \prime} \mathrm{E}, 1323 \mathrm{~m}\right.$ a.s.l), Vietnam in September

* Corresponding author: E- Mail: cttha@iebr.vast.vn, Phone: +84-912 513505. 


\section{Essential oil of Magnolia grandis}

2019. The voucher specimens (HG1924) were deposited at the Herbarium of Institute of Ecology and Biological Resources (HN), Vietnam Academy of Science and Technology. Herein, the chemical composition as well as antimicrobial activity of essential oils from leaves, twigs and ripe fruits of this Magnolia species are reported.

\section{Previous Studies}

Magnolia grandis (syn. Manglietia grandis Hu \& W.C.Cheng) is a large evergreen tree species that distributes in China and Vietnam [1-3]. The species is used for timber [2] and evaluated as critically endangered species [4]. Some studies involved in this species includes: Sowing seeds and planting the seedlings in Ha Giang province of Vietnam by FFI (Fauna \& Flora International) [5], research on seed germination in China [6], and research on genetic diversity and population differentiation in China [7]. Studies on the essential oil of this species are not found until now.

\section{Present Study}

Hydrodistillation of 1.6-2.5 kg of each of the shredded fresh leaves, twigs and ripe fruits of $M$. grandis produced pale yellow oils with the respective essential oil yields of $0.09 \pm 0.01 \%, 0.25 \pm 0.01$, and $0.62 \pm 0.02$ calculated on a dry weight basis.

The average relative densities of the oils were $d^{20}=0.90,0.87$, and 0.87 , the refractive indices were $n^{20}=1.48,1.47$, and 1.47 ; and the optical rotations were $[\alpha]_{0}^{20}=-16.13^{\circ},-17.80^{\circ}$, and $+20.32^{\circ}$, respectively.

The specific activity of the ripe fruit oil $\left(+20.32^{\circ}\right)$ was remarkably different from those of the leaf and twig oils $\left(-16.13^{\circ}\right.$ and $-17.80^{\circ}$, respectively), suggesting that there are more of the dextrorotary enantiomers of some of the main constituents $(\alpha$-pinene, $\beta$-pinene, linalool, and $(E)-\beta$ caryophyllene) in the fruit oil than those in the other oils. It's probably due to $\alpha$-pinene with high concentrations in the oils. Especially, $(+)$ - $\alpha$-pinene with its high value of optical activity $\left(+52.4^{\circ}\right)$ could be the major enantiomer in the fruit oil [8].

The identification of compounds present in the M. grandis essential oils collected in Ta Poc Mountains, Tung Vai Commune, Quan Ba District, Ha Giang Province, Vietnam was carried out using mass spectral (MS) and retention index (RI) data. Table 1 presents the identified compounds in order of their elution on the HP-5MS column used for the GC-MS analysis.

A total of 48,37 and 37 compounds representing $98.0 \%, 99.7 \%$ and $98.3 \%$ of the compositions were identified in the leaf, twig and ripe fruit essential oils, respectively, of M. grandis. These were comprised of monoterpene hydrocarbons $(25.7 \%, 77.8 \%$ and $70.9 \%)$, oxygenated monoterpenes $(31.8 \%, 13.3 \%$ and $12.5 \%)$, sesquiterpene hydrocarbons $(23.9 \%, 5.3 \%$ and $9.8 \%)$, oxygenated sesquiterpenes $(16.2 \%, 3.2 \%$ and $4.5 \%)$ of the respective leaf, twig, and ripe fruit oils. Benzenoid aromatics were only $1.0 \%, 0.6 \%$ and $1.2 \%$ of respective oil concentrations.

In the leaf oil, the major constituents were $\alpha$-pinene $(11.8 \%)$, linalool $(15.4 \%)$, and $(E)-\beta$ caryophyllene $(10.7 \%)$. Other notable constituents in leaf oil were $\beta$-pinene (7.4\%), 1,8-cineole (4.7\%), and $\alpha$-humulene (5.3\%). In the twig oil, the major constituents were $\alpha$-pinene (42.8\%) and $\beta$ pinene (23.7\%). Following this, limonene (3.7\%), 1,8-cineole (5.6\%) and $(E)-\beta$-caryophyllene (3.0\%) had significant amounts in the twig oil. In contrast to the leaf and twig oils, the ripe fruit oil contained $\alpha$-pinene (52.2\%) as its unique major compound. Other constituents that were present in the ripe fruit oil with sizable amounts consisted of: $\beta$-pinene (7.7\%), 1,8-cineole (3.9\%), and $(E)-\beta$-caryophyllene $(6.0 \%)$ (Table 1).

The common feature of these oil samples was that they contain $\alpha$-pinene as a main component of the oils. In addition, all of three analyzed oil samples were richer in monoterpene compounds than in sesquiterpene compounds. The main compounds in the oils of $M$. grandis species in the present study were different to those of other Magnolias, for example, $(Z)$ - $\beta$-ocimene (36.5\%), $(E)$ - $\beta$-ocimene (30.8\%) and germacrene A $(9.6 \%)$ were the main compounds of $M$. acuminata leaf oil; $\beta$-pinene (64.4\% and 37.4\%) of $M$. calophylla and $M$. virginiana leaf oils; $(Z)-\beta$-ocimene (15.2\%), germacrene A (12.9\%) and $\beta$-bisabolene (13.3\%) of $M$. grandiflora leaf oil [9]; $\beta$-pinene (23.0\%, 32.3\%, 12.7\% 
and $6.9 \%), 1,8$-cineole $(4.1 \%, 4.4 \%, 4.5 \%$ and $12.2 \%), \beta$-elemene $(13.6 \%, 7.7 \%, 12.9 \%$ and $5.7 \%)$ were the main compounds of $M$. grandiflora leaf, flower, immature fruit and mature fruit oils [10]; $\alpha$ terpinene $(12.73 \%)$, bicyclogermacrene $(10.25 \%)$, and aristolene $(28.51 \%)$ were the main compounds of M. figo leaf oi [11], naphthalene (35.1\%), and $\alpha$-bulnesene (10.1\%) were the main compounds of M. ovata (syn. Talauma ovata) fruit oi [12]. The variation of essential oil of one plant species or of different plant species may due to various factors such as seasons in the year [13,14], development stage of plants [15], geographic regions, etc., as well as genetic differences.

Table 1. Essential oil composition (\%) of the leaves, twigs and ripe fruits of $M$. grandis

\begin{tabular}{|c|c|c|c|c|c|}
\hline Compounds $^{\mathrm{a}}$ & $\mathbf{R I}^{\mathbf{b}}$ & $\mathbf{R I ^ { \mathbf { c } } , \mathbf { d } , \mathbf { e }}$ & Leaves $^{f}$ & Twigs $^{f}$ & Ripe fruits ${ }^{f}$ \\
\hline$\alpha$-Thujene & 930 & $909-937^{c}$ & - & 0.3 & - \\
\hline$\alpha$-Pinene & 939 & $912-944^{c}$ & 11.8 & 42.8 & 52.2 \\
\hline Camphene & 955 & $930-969^{c}$ & 1.2 & 2.6 & 1.6 \\
\hline Sabinene & 978 & $945-980^{c}$ & 0.3 & 0.3 & - \\
\hline$\beta$-Pinene & 984 & $958-997^{\mathrm{c}}$ & 7.4 & 23.7 & 7.5 \\
\hline Myrcene & 991 & $955-998^{c}$ & 0.7 & 1.7 & 3.3 \\
\hline$\alpha$-Phellandrene & 1009 & $966-1010^{c}$ & - & - & 0.2 \\
\hline$\alpha$-Terpinene & 1021 & $1007-1057^{c}$ & 0.2 & 0.4 & - \\
\hline$o$-Cymene & 1029 & $1015-1039^{c}$ & 0.4 & 0.5 & 0.5 \\
\hline Limonene & 1033 & $995-1037^{c}$ & 1.8 & 3.7 & 1.9 \\
\hline$\beta$-Phellandrene & 1035 & $995-1036^{c}$ & 0.7 & 0.7 & 3.5 \\
\hline 1,8-Cineole & 1037 & $1002-1046^{\mathrm{c}}$ & 4.7 & 5.6 & 3.9 \\
\hline$(E)$ - $\beta$-Ocimene & 1048 & $1015-1056^{\mathrm{c}}$ & 0.5 & 0.2 & 0.2 \\
\hline$\gamma$-Terpinene & 1062 & $1023-1067^{\mathrm{c}}$ & 0.3 & 0.5 & - \\
\hline cis-Sabinene hydrate & 1072 & $1033-1099^{\mathrm{c}}$ & 0.2 & - & - \\
\hline Terpinolene & 1094 & $1052-1094^{\mathrm{c}}$ & 0.2 & 0.4 & - \\
\hline Linalool & 1101 & $1062-1125^{\mathrm{c}}$ & 15.4 & 2.2 & 1.8 \\
\hline trans-Sabinene hydrate & 1104 & $1033-1112^{c}$ & 0.2 & - & 0.1 \\
\hline endo-Fenchol & 1121 & $1111-1134^{\mathrm{c}}$ & - & 0.1 & - \\
\hline trans-Sabinol & 1148 & $1136-1149^{c}$ & - & - & 0.2 \\
\hline cis-Sabinol & 1151 & $1136-1149^{c}$ & - & - & 0.2 \\
\hline Borneol (=endo-Borneol) & 1174 & $1134-1205^{\mathrm{c}}$ & 1.7 & 0.5 & 0.6 \\
\hline Terpinen-4-ol & 1185 & $1140-1207^{\mathrm{c}}$ & 1.0 & 1.3 & 0.4 \\
\hline$\alpha$-Terpineol & 1197 & $1153-1224^{\mathrm{c}}$ & 1.9 & 1.8 & 1.4 \\
\hline Methyl chavicol (=Estragole) & 1203 & $1190-1203^{c}$ & - & - & 0.1 \\
\hline Myrtenol & 1204 & $1176-1209^{c}$ & - & - & 0.1 \\
\hline Citronellol & 1228 & $1212-1266^{\mathrm{c}}$ & 1.1 & 0.2 & 1.6 \\
\hline Nerol & 1231 & $1202-1237^{\mathrm{c}}$ & 0.1 & - & 0.2 \\
\hline Chavicol & 1253 & $1259^{\mathrm{c}}$ & 0.4 & 0.1 & 0.6 \\
\hline Geraniol & 1255 & $1232-1301^{\mathrm{c}}$ & 3.4 & 0.4 & 0.5 \\
\hline Geranial & 1273 & $1269-1273^{\mathrm{c}}$ & 0.2 & - & - \\
\hline Bornyl acetate & 1293 & $1236-1295^{\mathrm{c}}$ & 1.0 & 1.0 & 1.3 \\
\hline Geranyl acetate & 1383 & $1377-1396^{c}$ & 1.1 & 0.2 & 0.1 \\
\hline$\alpha$-Copaene & 1389 & $1335-1419^{c}$ & 0.2 & 0.2 & 0.2 \\
\hline Cascarilladiene & 1432 & $1436^{\mathrm{d}}$ & 1.5 & - & - \\
\hline (E)- $\beta$-Caryophyllene & 1437 & $1395-1462^{\mathrm{c}}$ & 10.7 & 3.0 & 6.0 \\
\hline Aromadendrene & 1456 & $1429-1472^{c}$ & 0.3 & - & - \\
\hline$\alpha$-Humulene & 1471 & $1418-1495^{\mathrm{c}}$ & 5.3 & 1.3 & 2.8 \\
\hline$\delta$-Selinene & 1504 & $1483-1500^{c}$ & 1.1 & 0.2 & 0.2 \\
\hline$(E, E)-\alpha$-Farnesene & 1511 & $1463-1545^{\mathrm{c}}$ & 2.4 & - & - \\
\hline$\alpha$-Selinene & 1512 & $1470-1503^{c}$ & 0.8 & 0.2 & 0.2 \\
\hline$\gamma$-Cadinene & 1530 & $1470-1553^{c}$ & 0.2 & - & - \\
\hline$\delta$-Cadinene & 1536 & $1480-1562^{\mathrm{c}}$ & 0.5 & 0.2 & 0.4 \\
\hline trans-Calamenene & 1537 & $1495-1528^{c}$ & 0.2 & - & - \\
\hline Elemol & 1562 & $1545-1565^{\mathrm{c}}$ & - & 0.2 & - \\
\hline (E)-Nerolidol & 1568 & $1530-1583^{c}$ & 4.1 & - & - \\
\hline
\end{tabular}


Essential oil of Magnolia grandis

Table 1 continued..

\begin{tabular}{|c|c|c|c|c|c|}
\hline Eudesma-5,7(11)-diene & 1572 & $1543^{\mathrm{e}}$ & 0.7 & 0.2 & - \\
\hline Spathulenol & 1596 & $1543-1624^{c}$ & 0.3 & - & - \\
\hline Caryophyllene oxide & 1603 & $1548-1611^{\mathrm{c}}$ & 4.2 & 0.7 & 2 \\
\hline Humulene epoxide I & 1618 & $1607^{\mathrm{c}}$ & 0.3 & - & - \\
\hline Humulene epoxide II & 1630 & $1579-1652^{c}$ & 1.5 & 0.2 & 0.8 \\
\hline$\gamma$-Eudesmol & 1649 & $1621-1647^{c}$ & 0.6 & 0.4 & 0.2 \\
\hline epi- $\alpha$-Cadinol (= $\tau$-Cadinol) & 1656 & $1616-1665^{c}$ & 0.5 & - & - \\
\hline$\beta$-Eudesmol & 1670 & $1642-1667^{c}$ & 1.5 & 0.8 & 0.5 \\
\hline$\alpha$-Eudesmol & 1673 & $1649-1670^{c}$ & 1.6 & 0.9 & 0.7 \\
\hline 14-hydroxy-9-epi-(E)-Caryophyllene & 1688 & $1702^{\mathrm{c}}$ & - & - & 0.3 \\
\hline$(E, E)$-Farnesol & 1726 & $1722-1727^{c}$ & 1.6 & - & - \\
\hline \multicolumn{3}{|c|}{ Total identified } & 98.0 & 99.7 & 98.3 \\
\hline \multicolumn{3}{|c|}{ Monoterpene hydrocarbons } & 25.7 & 77.8 & 70.9 \\
\hline \multicolumn{3}{|c|}{ Oxygenated monoterpenes } & 31.8 & 13.3 & 12.5 \\
\hline \multicolumn{3}{|c|}{ Sesquiterpene hydrocarbons } & 23.9 & 5.3 & 9.8 \\
\hline \multicolumn{3}{|c|}{ Oxygenated sesquiterpenes } & 16.2 & 3.2 & 4.5 \\
\hline \multicolumn{3}{|c|}{ Others } & 0.4 & 0.1 & 0.6 \\
\hline
\end{tabular}

Note: ${ }^{\mathrm{a}}$ Elution order on HP-5MS column; ${ }^{\mathrm{b}}$ Retention indices on HP-5MS column; ${ }^{\mathrm{c}, \mathrm{d}, \mathrm{e}}$ Literature retention indices ${ }^{\mathrm{c}}[16]$ on HP-5MS column; d $[17]$; ${ }^{e}[18]$; Standard deviation were insignificant and excluded from the Table to avoid congestion; (-) Not identified.

Essential oils of $M$. grandis were then determined the minimum inhibitory concentration (MIC) and median inhibitory concentration $\left(\mathrm{IC}_{50}\right)$ values through microbroth dilution assays [19-20] using 7 strains of microorganisms: Staphylococcus aureus, Bacillus subtilis, and Lactobacillus fermentum, Salmonella enterica, Escherichia coli, Pseudomonas aeruginosa, and Candida albicans. The results of the assay evaluated after 16-24 hours of incubation are presented in Table 2. Although the antimicrobial activities of $M$. grandis essential oils were marginal at best [20], the leaf essential oil from $M$. grandis expressed stronger inhibitory effects on the seven test microorganisms than the twig and ripe fruit oils. $\mathrm{IC}_{50}$ values of the $M$. grandis leaf, twig and ripe fruit oils were from 683 to 7851 $\mu \mathrm{g} / \mathrm{mL}$, from 1499 to $10,012 \mu \mathrm{g} / \mathrm{mL}$ and from 939 to $6599 \mu \mathrm{g} / \mathrm{mL}$. MIC values of these oils ranged from 2048 to $>16,384 \mu \mathrm{g} / \mathrm{mL}$, from 8192 to $>16,384 \mu \mathrm{g} / \mathrm{mL}$ and from 4096 to $>16,384 \mu \mathrm{g} / \mathrm{mL}$, respectively. S. aureus, E. coli, and $C$. albicans were more sensitive to the essential oils than four other tested microorganisms (Table 2). The higher activity of the M. grandis leaf oil could be associated with higher amounts of oxygenated monoterpenes and oxygenated sesquiterpenes than the ones in the twig and ripe fruit oils. Previous study demonstrated that essential oils rich in oxygenated compounds are more active as antimicrobial agents than essential oils with large amounts of hydrocarbons [21].

Table 2. MIC and $\mathrm{IC}_{50}$ of essential oils from leaves, twigs and ripe fruits of $M$. grandis

\begin{tabular}{lcccccc}
\hline Essential oil samples & \multicolumn{2}{c}{ Leaves } & \multicolumn{2}{c}{ Twigs } & \multicolumn{2}{c}{ Ripe fruits } \\
\hline Value $(\mu \mathrm{g} / \mathrm{mL})$ & $\mathrm{IC}_{50}$ & $\mathrm{MIC}$ & $\mathrm{IC}_{50}$ & $\mathrm{MIC}$ & $\mathrm{IC}_{50}$ & MIC \\
\hline S. aureus & 683 & 4096 & 1499 & 8192 & 939 & 4096 \\
B. subtilis & 2979 & 16,384 & 3959 & $>16, .384$ & 4578 & $>16,384$ \\
L. fermentum & 7851 & $>16,384$ & 10,012 & $>16,384$ & 6599 & $>16,384$ \\
S. enterica & 4096 & 16,384 & 2993 & 16,384 & 4876 & $>16,384$ \\
E. coli & 1365 & 4096 & 1994 & 8192 & 1832 & 8192 \\
P. aeruginosa & 3823 & $>16,384$ & 7877 & $>16,384$ & 6144 & $>16,384$ \\
C. albicans & 728 & 2048 & 1950 & 8192 & 2010 & 8192 \\
\hline
\end{tabular}

The antimicrobial activity of essential oils varying on different microorganisms can be derived from their main compounds or the synergism of many of their components. $\alpha$-pinene, $\beta$-pinene, linalool, and $(E)-\beta$-caryophyllene being main components of essential oil samples in the present study may contribute the great role in antimicrobial activities. In the past, antimicrobial potential of some essential oil components against some tested microbial strains were presented as: Linalyl acetate < limonene $<\beta$-pinene $<\alpha$-pinene $<$ camphor $<$ linalool $<1,8$-cineole $<$ menthol $<$ thymol $<$ carvacrol 
[22]. Other previous studies indicated the antimicrobial activity of $(E)-\beta$-caryophyllene against different microbial strains including $S$. aureus, E. coli [23-25] with its lower antimicrobial activity against $E$. coli than those of $\beta$-pinene, linalool [24] or higher than those of $\alpha$-pinene, $\beta$-pinene [25]. It was commented that the magnitude of synergic interaction between different essential oils was low but the synergism between essential oils and food additives was strong [21]. This leads to using smaller amounts of flavored food preservatives that should be helpful for food industry.

In conclusion, the research results provide the first information on the chemical composition and antimicrobial activity of the essential oils from leaves, twigs and ripe fruits of $M$. grandis. Among 48, 37 and 37 compounds identified in of the oils, major components consisted of: $\alpha$-pinene (11.8\%), linalool (15.4\%), and (E)- $\beta$-caryophyllene (10.7\%) (leaf oil); $\alpha$-pinene (42.8\%) and $\beta$-pinene (23.7\%) (twig oil); and $\alpha$-pinene (52.2\%) (ripe fruit oil). The leaf essential oil from $M$. grandis had the stronger inhibitory effects on the seven tested microorganisms than the twig and ripe fruit oils. The results of present study can be the basis for future research on the field of food and beverage industry as flavoring and preservative agents.

\section{Acknowledgments}

This research was funded by Vietnam National Foundation for Science and Technology Development (NAFOSTED) under Grant number 106.03-2019.16.

\section{Supporting Information}

Supporting Information accompanies this paper on http://www.acgpubs.org/journal/recordsofnatural-products

\section{ORCID}

Chu T. T. Ha: $\underline{0000-0002-3479-9469}$

Le N. Diep: 0000-0002-7219-6511

Dinh T. T. Thuy: 0000-0002-6687-9340

Trinh N. Bon: 0000-0001-7530-8008

Le T. T. Cham: 0000-0002-6215-7332

William N. Setzer: 0000-0002-3639-0528

\section{References}

[1] B. N. Tu, Q. H. Nguyen and T. H. Nguyen (2015). Five new records of Magnoliaceae Juss for the flora of Vietnam. Proceedings of the $6^{\text {th }}$ National conferences on ecology and biological resources; Oct $21^{\text {st; Hanoi, }}$ Vietnam. Institute of Ecology and Biological Resources, 243-248.

[2] B. L. Chen and H. P. Nooteboom (1993). Notes on Magnoliaceae III: The Magnoliaceae of China, Ann. Missouri Bot. Gard. 80(4), 999-1104.

[3] The plant list (2021). http://www.theplantlist.org/tpl1.1/record/kew-344365, (retrieved Dec. 12, 2021).

[4] The IUCN Red List of Threatened Species version 2021-1, 2021: https://www.iucnredlist.org/. Downloaded on 20 May 2021.

[5] D. Gill (2017). Sowing the seeds of hope for critically endangered magnolia tree. Fauna \& Flora International. https://www.fauna-flora.org/news/sowing-the-seeds-of-hope-for-critically-endangeredmagnolia-tree (retrieved June 2, 2021).

[6] R. Pan and W. B. Sun (2009). Seed dormancy and germination of the critically endangered Manglietia grandis Hu et Cheng, Plant Physiol. Commun. 45, 1089-1092.

[7] T. Xu (2020). The genetic diversity and population differentiation of Magnolia grandis, an endangered and potential herbal medicine plant in China, Basic Clin. Pharmacol. Toxicol. 126, 38-39.

[8] S. Dev (Ed.) (1982). CRC Handbook of Terpenoids - Monoterpenoids, Volume II, CRC Press, Florida, p. 449.

[9] M. A. Farag, R. S. E. Din and S. Fahmy (2015). Headspace analysis of volatile compounds coupled to chemometrics in leaves from the Magnoliaceae family, Rec. Nat. Prod. 9 (1), 153-158.

[10] A. Ali, N, Tabanca, B, Demirci, V. Raman, J. M. Budel, K. H. C. Baser and A. A. Khan (2020). Insecticidal and biting deterrent activities of Magnolia grandiflora essential oils and selected pure compounds against Aedes aegypti, Molecules 25, 1359. 


\section{Essential oil of Magnolia grandis}

[11] Y. Ma, H. Zhang, R. Song, Z. Wang and B. Yang (2012). Study on antimicrobial activity and chemical components of essential oil from Michelia figo Spreng leaves, Adv. Mat. Res. 518-523, 509-515.

[12] M. É. A. Stefanello and R. de Mello-Silva (2005). Volatile constituents of Talauma ovata A. St.Hil. fruits, J. Essent. Oil Res. 17(4), 455-456.

[13] J. H. G. Lago, O. A. Fávero and P. Romoff (2009). Chemical composition and seasonal variation of the volatile oils from leaves of Michelia champaca L., Magnoliaceae, Rev. Bras. Farmacogn. 19(4), 880-882.

[14] M. É. A. Stefanello, M. F. Salvador, I. Y. Ito, A. Wisniewski Jr, E. L. Simionatto and R. de Mello-Silva (2008). Chemical composition, seasonal variation and evaluation of antimicrobial activity of essential oils of Talauma ovata A. St. Hil. (Magnoliaceae), J. Essent. Oil Res. 20(6), 565-569.

[15] S. Sanimah, R. Suri, R. N. Azizun, A. Hazniza, M. Radzali, I. Rusli and M. D. Hassan (2008). Volatile compounds of essential oil from different stages of Michelia alba (cempaka putih) flower development, J. Trop. Agric. and Fd. Sc. 36 (1), 109-119.

[16] P. J. Linstrom and W. G. Mallard (2021). NIST chemistry webbook, NIST standard reference database number 69, National Institute of Standards and Technology, Gaithersburg M. D., 20899, (retrieved June 2, 2021).

[17] P. Pripdeevech, S. Wongpornchai and A. Promsiri (2006). Highly volatile constituents of Vetiveria zizanioides roots grown under different cultivation conditions, Molecules 11(10), 817-826.

[18] A. Wajs-Bonikowska, M. Sienkiewicz, A. Stobiecka, A. Macia g, Ł. Szoka and E. Karna (2015). Chemical composition and biological activity of Abies alba and A. koreana seed and cone essential oils and characterization of their seed hydrolates, Chem. Biodivers. 12 (3), 407-418.

[19] F. Hadacek and H. Greger (2000). Testing of antifungal natural products methodologies, comparability of result and assay choice, Phytochem. Anal. 11, 137-147.

[20] P. Cos, A. J. Vlietinck, D. V. Berghe and L. Maes (2006). Anti-infective potential of nature products: How to develop a stronger in vitro 'proof-of-concept', J. Ethnopharmacol. 106 (3), 290-302.

[21] D. Kalemba and A. Kunicka (2003) Antibacterial and antifungal properties of essential oils. Current Med. Chem. 10, 813-829.

[22] M. Soković, J. Glamočlija, P. D. Marin, D. Brkić and L. J. L. D. van Griensven (2010). Antibacterial effects of the essential oils of commonly consumed medicinal herbs using an in vitro model, Molecules 15, $7532-7546$.

[23] M. C. S. Neta, C. Vittorazzi, A. C. Guimarães, J. D. L. Martins, M. Fronza, D. C. Endringer and R. Scherer (2017). Effects of $\beta$-caryophyllene and Murraya paniculata essential oil in the murine hepatoma cells and in the bacteria and fungi 24-h time-kill curve studies. Pharm. Biol. 55 (1), 190-197.

[24] S. K. Nguikwie, M. A. Nyegue, F. N. F. Belinga, R. A. N. Ngane, B. Romestand, A, Kouzayha, H. Casabianca, P. H. A. Zollo and C. Menut (2013). The chemical composition and antibacterial activities of the essential oils from three Aframomum species from Cameroon, and their potential as sources of $(E)-(R)$ nerolidol, Nat. Prod. Commun. 8 (6), 829-834.

[25] C. Yang, D. H. Hu and Y. Feng (2015). Antibacterial activity and mode of action of the Artemisia capillaris essential oil and its constituents against respiratory tract infection-causing pathogens, Mol. Med. Rep. 11, 2852-2860.

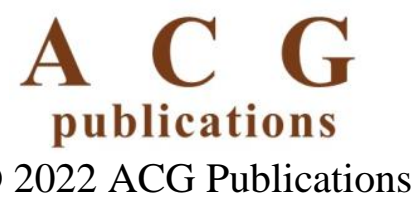

